\title{
PERFORMATIVIDADE E EDUCAÇÃO: a politica das avaliações em larga escala e a apropriação da midia
}

\author{
PERFORMATIVITY AND EDUCATION: wide-scale \\ evaluation policies and media appropriation
}

\author{
Rosimar Serena Siqueira Esquinsani*
}

\begin{abstract}
Resumo
O trabalho aborda a avaliação em larga escala na Educação Básica e a performatividade, ambas problematizadas a partir da apropriação da mídia de grande circulação enquanto estrutura que materializa e coloca em perspectiva, de alguma forma, o debate acerca da Educação nacional e dos princípios de qualidade da mesma, no escopo de adensar discussões (e olhares) sobre a qualidade na escola. Para tanto, o texto apoia-se em fontes documentais constituídas por 1.924 produtos midiáticos recolhidos a partir dos elementos disponíveis on-line nos sites de três importantes revistas semanais de circulação nacional, no recorte temporal de 1996 a 2007. Como conclusão o texto aponta que a mídia potencializa o caráter de performatividade das avaliações em larga escala, no contexto do Estado avaliador, na medida em que torna público e, portanto, relevante, os índices e indicadores de escolas e sistemas de ensino, focalizando a competição e o desempenho como parâmetros de qualidade.
\end{abstract}

Palavras-chave: Mídia. Educação. Avaliação em larga escala. Performatividade. Desempenho.

\begin{abstract}
The present paper addresses the wide-scale evaluation in Basic Education and the issue of performativity, both discussed in light of the appropriation of the mainstream media as a structure that embodies and somehow puts into perspective the debate over national education and its principles of quality, in the sense of condensing the discussion (and the views) about the quality of the schools. To this end, the text draws on documentary sources consisting of 1,924 media products collected from the information available online on the websites of three major weekly magazines of national circulation, in a time window from 1996 to 2007. In conclusion, the text points out that the media reinforces the performance-oriented aspects of the wide-scale evaluations in the context of the State as an evaluative agent, as it publicizes the scores and indicators of the schools and schooling systems, therefore making them relevant and focusing on the competition and performance as quality parameters.
\end{abstract}

Keywords: Media. Education. Wide-scale Evaluation. Performativity. Performance.

\section{Introdução}

Fruto de uma demanda histórica, o processo de universalização do acesso ao Ensino Fundamental desencadeado no Brasil ao longo do século XX obrigou as redes escolares - sobretudo as públicas - a (re)pensarem formas de organização e distribuição de recursos (espaciais, financeiros e humanos) que atentassem para a absorção (quantitativamente falando) dos alunos que procuravam por vagas na educação formal.

Tal situação levou a maior parte das escolas a operar no limite de sua capacidade, a fim de atender a uma demanda crescente por vagas, essas distribuídas, muitas vezes, em dois ou até mesmo em três turnos regulares de trabalho (manhã, tarde e noite), seguindo princípios de racionalização financeira e de um aproveitamento quase milimétrico das estruturas físicas das escolas.
Assim, a partir da segunda metade do século XX, ocorreu na Educação nacional o desvelo de uma contradição que atinge em cheio os sistemas de ensino: a ampliação do número de vagas - luta histórica compromissada com o acesso de todos à escola básica -, não significou necessariamente a garantia de qualidade na educação de todos. A partir disso, concluiu-se que não bastava colocar todos na escola, mas sim evidenciar formas qualitativas de administrar a expansão da escolarização.

No âmbito daquela conclusão, as avaliações em larga escala (Saeb, Prova Brasil, Enem, etc.) restaram por exercer o protagonismo, sobretudo em sua função de mostrar quantitativamente os indicadores da Educação nacional, trazendo a interpretação dos mesmos para o debate da sociedade.

Via de regra, os dados levantados na avaliação em grande escala precisam ser analisados, criticados, cotejados por agentes de diferentes níveis

\footnotetext{
* Professora do Programa de Pós-Graduação em Educação da Universidade de Passo Fundo. E-mail: rosimaresquinsani@upf.br
} 
envolvidos com a Educação, servindo não apenas para o ranking internacional e nacional, mas para o subsídio dos educadores e gestores da Educação em diferentes níveis, qualificando políticas públicas e processos de gestão da Educação.

Isso porque, ordinariamente, os dados apresentados por tais avaliações têm centrado o foco no rendimento do aluno e no desempenho dos sistemas de ensino, nutrindo o debate com informações que podem ser analisadas por toda ordem de teorias e estatísticas.

É nesse momento que entra em cena a mídia, assumindo certa proeminência, seja por divulgar a aplicação e os resultados das avaliações em larga escala; publicizar os indicadores educacionais produzidos por tais avaliações ou comentar resultados, fomentando, assim, a inclusão do tema na agenda da Educação nacional.

Destarte, o foco do trabalho tangencia a avaliação em larga escala na Educação Básica e a performatividade, ambas problematizadas a partir da apropriação da mídia de grande circulação enquanto estrutura que materializa e coloca em perspectiva, de alguma forma, o debate acerca da Educação nacional.

Por esse olhar, os textos examinados se alocam na ordem de discurso da imprensa, onde os principais gêneros são: o jornalismo informativo (nota, notícia, reportagem, entrevista) e o jornalismo opinativo (editoria, comentário, artigo, resenha e coluna) (MELO, 1994, p. 62) e que são, neste texto, representados por fragmentos empíricos.

Considera-se, ainda, que a mídia tem determinado cada vez mais o ponto de vista das sociedades modernas: "de uma forma profunda e irreversível, o desenvolvimento da mídia transformou a natureza da produção e do intercâmbio simbólicos no mundo moderno." (THOMPSON, 2001, p. 19). O discurso da mídia é ponto determinante na composição da pauta das discussões sociais. O cotidiano brota de suas colunas forjando opiniões e lançando temas aceitos e entendidos como relevantes e dignos de discussão pela sociedade.

Portanto, a escolha do tema sob o foco da mídia não é casuística, uma vez que "as lutas concretas de cada sociedade são postas em cena nos textos da mídia, especialmente na mídia comercial da indústria cultural cujos textos devem repercutir as preocupações da sociedade, se quiserem ser populares e lucrativos". (KELLNER, 2002, p. 32).

\section{Avaliação em larga escala: da promessa a uma política consolidada}

A gênese das avaliações em larga escala poderia, sem grande esforço, ser buscada junto à configuração do Estado avaliador e a toda a série de pressupostos teórico-ideológicos e instrumentos de atuação que vieram em seu bojo.

O Estado avaliador pode ser conceituado como o Estado que adota "um ethos competitivo, neodarwinista, passando a admitir a lógica do mercado, através da importação para o domínio público de modelos de gestão privada, com ênfase nos resultados ou produtos dos sistemas educativos". (AFONSO, 2009, p. 49).

Partindo dessa perspectiva, o Estado avaliador legitima o controle social sobre o trabalho docente (aferição de resultados), sendo que

[...] de certa forma, pode-se dizer que, valendo-se de argumentos que atraem o interesse público pelos seus apelos democráticos, esse tipo de Estado exerce sua função com a adesão de grandes setores da população. A emergência e o desenvolvimento do Estado avaliador são justificados e legitimados como uma importante maneira de tornar transparente para o público a forma como as instituições atuam e utilizam os recursos públicos. (SANTOS, 2004, p. 1151-1152).

Esse Estado é pautado pela racionalidade financeira e produtividade, onde "a ordem é reduzir o insucesso para alcançar menos desperdício de recursos humanos e materiais" (SHIROMA; MORAES; EVANGELISTA, 2002, p. 13), autolegitimando-se através de práticas pretensamente transparentes, consolidando a política em avaliações de larga escala onde o emprego do dinheiro público é traduzido em serviços educacionais e resultados mensuráveis. No contexto do Estado avaliador, "a fé em indicadores mensuráveis passa a ser o exemplo paradigmático das mudanças neoliberais e neoconservadoras". (AFONSO, 2009, p. 50).

Com esse pano de fundo, a emergência da regulação avaliativa no campo da Educação se deu no percurso da configuração de um novo modelo de gestão: as avaliações em larga escala como subsídios para ações e políticas educacionais (tripé avaliação - informação - ação). Dessa sorte, as avaliações externas apresentaram-se como via de regulação estatal da Educação, consolidando o Estado avaliador e perpetrando a "cultura do desempenho" (SANTOS, 2004, p. 1151), tão referenciada contemporaneamente.

Nesse contexto, surgem os primeiros ensaios da avaliação de sistema, que "refere-se à aferição padronizada do rendimento escolar dos alunos, realizada no âmbito do sistema nacional ou dos sistemas estaduais de avaliação do ensino básico" (BARRETTO et al., 2001, p. 51), atualmente conhecidas como avaliações em larga escala.

Entendo que um sistema de avaliação (WAISELFISZ, 1993, p. 6) constitui uma sequência 
periódica e ininterrupta de processos ou atividades de levantamento, tratamento e difusão de resultados. Dessa sorte, as avaliações em larga escala se articulam a esse conceito de sistema de avaliação. Entretanto, há que discutir seus dados, dispô-los frente a outras referências e práticas, pois elementos quantitativos não produzem avaliação, ou seja, só há avaliação quando o qualitativo emergir do quantitativo. Há que especialmente discuti-los com os educadores, com pais, gestores educacionais e a comunidade em geral em um nível que não seja o das sínteses estatísticas nacionais e estaduais, tão distanciado e abstrato, mas de forma que processos e resultados possam ser reconhecidos e desdobrados localmente em seus significados.

Por outro lado, sabendo que a avaliação se desenvolve em vários níveis - um dos quais implica em confronto de dados de uma realidade com outros que se constituem em nível do ideal, do dever-ser, do projetado, do intencionado (HADJI, 1994) -, a discussão dos produtos da avaliação em larga escala na mídia coloca o tema Educação na agenda do debate nacional.

Dessa sorte, a avaliação em larga escala constitui-se em tendência vislumbrada nos diversos níveis da administração pública em todo o país e por diferentes partidos políticos: as avaliações externas enquanto via de regulação estatal da Educação, consolidada ao longo da década de 1990, tornandose uma das mais efetivas políticas públicas para o campo da Educação nos dias atuais.

Os diferentes e reiterados tipos de críticas aos chamados 'ineficientes sistemas burocráticos de governo' deram abertura e legitimidade à penetração crescente de uma nova lógica de administração derivada do setor privado. Essa nova lógica lentamente vai introduzindo formas, muitas vezes bastante sutis, de privatização, mas seu elemento-chave é a análise de desempenho de pessoas e de instituições. A garantia da implementação de políticas, que se estruturam e se desenvolvem com base na cultura do desempenho, é assegurada pela criação do Estado avaliador. (SANTOS, 2004, p. 1.151).

De outra forma, as avaliações em larga escala representam o Estado avaliador na medida em que

[...] expressam, no limite, uma concepção acerca do papel do Estado na condução das políticas educacionais. Ao que parece, a questão central nesta proposta não é a de buscar subsídios para intervenções mais precisas e consistentes do poder público, ou seja, uma análise das informações coletadas para definição e implementação de políticas para a educação básica, mas sim difundir, nos sistemas escolares, uma dada concepção de avaliação, que tem como finalidade a instalação de mecanismos que estimulem a competição entre as escolas, responsabilizando-as, em última instância, pelo sucesso ou fracasso escolar. (SOUZA; OLIVEIRA, 2003, p. 881).
Eis o desenho da performatividade que, grosso modo, pode ser definida como um critério que visa traduzir tudo em lucro econômico a todo custo. Associam-se, nesse sentido, palavras como eficácia, eficiência, produção, rendimento, etc.

No que concerne à Educação, a performatividade tem sido responsável por delinear "uma nova arquitetura para o setor educacional, edificada a partir de critérios de eficiência e eficácia em consonância com os interesses do mercado, que alicerçam mudanças de várias ordens nos sistemas de ensino". (SANTOS, 2004, p. 1.146).

Nessa lógica, a vinculação entre performatividade e aferições de qualquer natureza no campo educacional (desde testes de larga escala até as avaliações rotineiras que acontecem no interior dos sistemas e unidades educativas) é até simplista, pois que na performatividade

Os desempenhos (de sujeitos individuais ou orga-
nizações) servem como medidas de produtividade
e rendimento, ou mostras de qualidade ou ainda
momentos de promoção ou inspecção. Significam,
englobam e representam a qualidade, a validade
ou valor de um indivíduo ou organização dentro de
um determinado âmbito de julgamento/ avaliação.
(BALL, 2002, p. 4).

O desempenho, a comparação e a competição meritocrática passam a ser marcas de produção e motivos para deferência e diferenciação dentro de sistemas educacionais, sendo que os não adaptados, os resultados pífios, os problemas internos (e inerentes) aos próprios sistemas são considerados como falhas na performance. Não há uma reflexão consubstanciada sobre os processos e tampouco o critério de performatividade permitiria tal reflexão.

As aferições de aprendizagem a partir de modelos pré-estabelecidos (e fechados) são festejadas e respeitadas, tendo em vista que possibilitam o controle do sistema de produção, eficiência e eficácia, sem o qual o rendimento oscilaria.

\section{Considerações pertinentes sobre a mídia}

Contemporaneamente, a cultura da mídia é responsável pela construção e circulação de um amplo leque de imagens, códigos e informações. A mídia detém, ainda, uma inigualável capacidade de disseminação e alcance de seus conteúdos e representações acerca da realidade social. Fica claro, portanto, que o impacto social dos conteúdos que ela difunde não pode ser menosprezado.

A mídia, por seu papel nas sociedades contemporâneas, possui o condão de determinar a pauta do que será notícia. Assim, a mídia promove certos temas e compõe a agenda do que será discutido (e, portanto, considerado relevante), a partir do 
momento que escolhe o que será notícia. Ao fazer circular tais temas, constrói crenças de que esses são os problemas importantes sobre os quais devemos pensar e nos posicionar. Ao decidir o que será notícia, a mídia também decide - de certa maneira -, nossos amores, gostos e problemas.

Ininterruptamente, constrói modelos sobre o bem e o mal, o certo e o errado, a justiça, a beleza, a política (e as formas de fazê-la), que podem legitimar ou desqualificar determinadas práticas; evidenciar pontos de vista, tornando-os majoritários; e neutralizar opiniões adversas.

Sobre esse assunto, Kellner (2002, p. 27) aduz que:

A cultura veiculada pela mídia transformou-se numa força dominante de socialização: suas imagens e celebridades substituem a família, a escola e a lgreja como árbitros de gosto; valor do pensamento, produzindo novos modelos de identificação e imagens vibrantes de estilo, moda e comportamento.

Assim, os meios de comunicação, de acordo com suas premissas editoriais, selecionam e fazem os recortes sobre o que será divulgado (e como o será), o que impinge ao jornalismo um caráter de detentor de sentidos, produtor de verdades, sobretudo em relação "a mais fundamental conquista da mídia contemporânea, sobretudo a mídia factual: sua capacidade de nos convencer de que o que ela representa realmente ocorreu". (SILVERSTONE, 2002, p. 67).

Através das páginas de uma revista semanal, exemplarmente, a mídia é capaz de produzir desdobramentos para os seus discursos, consubstanciados em certezas: formação de opinião. Através dos seus discursos sobre os mais diferentes temas, a mídia forma opiniões e condiciona argumentos sobre os temas que lança em pauta.

A mídia encontra-se presente em todo o universo social, plasmando-se as compreensões que o indivíduo faz sobre os elementos da realidade que o cerca, pois o mesmo absorve as experiências da superfície do mundo, incorporando-as ao seu dia-adia (SILVERSTONE, 2002) a partir de um ponto de vista não reflexivo.

Dentro do contexto cotidiano, a mídia informativa (como os jornais e as revistas, por exemplo) é especialmente importante, já que ela se torna - direta ou indiretamente - uma fonte essencial de fornecimento dos recursos de que a população dispõe para informar-se. Assim, aquilo que os meios de informação veiculam ou deixam de veicular é significativo do ponto de vista da percepção da realidade social que está disponível para os consumidores.

Esta lógica "informativa" vem no bojo do próprio conceito de jornalismo, e dos ideais a partir do qual ele foi inspirado
[...] o jornalismo é a síntese do espírito moderno: a razão (a verdade, a transparência) impondo-se diante da tradição obscurantista, o questionamento de todas as autoridades, a crítica da política e a confiança irrestrita no progresso e no aperfeiçoamento contínuo da espécie. (MARCONDES FILHO, 2000, p. 9).

A ideia gênese é de um conhecimento, um saber (a notícia, a informação, a fala de alguém que por alguma razão aguce a curiosidade e/ou a expectativa) que circule de forma mais ou menos livre (MARCONDES FILHO, 2000), o que gerou a chamada "mitologia da profissão", ou seja, o mito de que o veículo de comunicação (o jornalismo e o jornalista, por conseguinte) é objetivo, imparcial e tem um compromisso com a verdade. (SILVA, 2001, p. 9). Já Marcondes Filho (2000, p. 9) soma mais um a esses mitos: o mito da transparência simbioticamente ligado ao mito da isenção. Silva (2001, p. 35) diz, por exemplo, que isenção é o "[...] nome que se dá à opinião que recebe o apoio de um grupo em condição de fazer valer as suas ideias em determinada situação".

Todavia, a relação da mídia com o campo da Educação é eivada por uma série de percalços, argumentos e contra-argumentos que definem, indelevelmente, a agenda da Educação no próprio movimento de contradição, pois,

Educação e Media são campos de formação de conceitos, preconceitos, consciências, subjetividades e áreas construtoras privilegiadas da opinião pública. Pois, além de tratarem de cultura, de valores e informação, são campos também veiculadores de ideologia, uma vez que utilizam em suas ações a linguagem. E ao utilizar-se o signo lingüístico para construir processos de significação, tanto o campo Mediático, por meio de seus agentes, os jornalistas -, quanto as Ciências da Educação, por meio dos professores e investigadores, estão agindo nos campos da ideologia e do poder. Tais sujeitos se constituem em ideólogos e agentes de conhecimentos autorizados em suas respectivas áreas. (FREITAS, 2009, p. 2).

Sendo assim, nos discursos produzidos e em contraposição aos discursos produzidos pela Educação, a mídia é capaz de ratificar estereótipos ou, se assim desejar, produzir sentidos que tragam o tema para o centro do debate social mais amplo, formando a agenda da Educação.

Como alerta Silverstone: "Não podemos escapar à mídia [...] ela está presente em todos os aspectos da vida cotidiana". (2002, p. 9). A mídia, através dos seus documentos de domínio público, é capaz de fazer chegar a um maior número de pessoas o debate social acerca da Educação nacional, sendo materialmente relevante a apropriação que a mesma faz das avaliações em larga escala, atualmente consideradas como o tema da moda no que se refere à Educação. 
Performatividade e educação: a política das avaliações em larga escala e a apropriação...

\section{Leituras a partir dos resultados da pesquisa empírica}

Ao propor uma discussão sobre a assimilação que a mídia faz acerca da performatividade na Educação, a partir dos resultados das avaliações de larga escala, o texto aporta-se em fontes documentais. Tais fontes constituem-se em 1.924 produtos midiáticos recolhidos a partir dos elementos disponíveis on-line nos sites de três importantes revistas semanais de circulação nacional: Veja, Isto É e Época, no recorte temporal de 1996 a 2007.

Importante fazer duas observações em relação ao texto: primeiro tratam-se de fragmentos exemplares dos produtos midiáticos analisados, sem a pretensão de mostrar todos os recortes ao longo do texto. A segunda observação informa que, que para fins desde texto, o exame dos produtos midiáticos foi desdobrado em três categorias de análise.

Em relação à primeira categoria, é interessante observar que, dos diversos dados coletados no percurso empírico, chama atenção o número de produtos midiáticos que colocam o professor como responsável pelos resultados das avaliações de larga escala ( $87 \%$ dos produtos selecionados sobre o tema). Seja como o grande responsável pela melhoria da Educação; ou como o "vilão" (seja pelo seu despreparo, seja pelas condições de trabalho), o professor ocupa lugar central nas discussões encetadas pela mídia.

Nesse sentido, parece haver uma redução dos sistemas escolares e unidades educativas ao papel/função do professor, sendo que o mesmo é visto isoladamente, tanto como parte do problema (ineficiência), como parte da solução (superação individual, meritocracia e esforço próprio). Cria-se uma responsabilização unilateral absurda onde o professor torna-se o responsável tanto pelo fracasso quanto pelo sucesso de redes e sistemas educacionais inteiros.

Como desdobramento da primeira categoria acena-se para a forja frequente da figura exemplar/ modelar do docente que com esforço e superação transpõe barreiras para promover uma Educação de qualidade, à revelia dos sistemas e outros agentes educativos aos quais se vincula.

Por seu turno, e como segunda categoria de análise, é perceptível a valorização exacerbada que a mídia transfere aos índices, à performance. Nessa direção, a busca/culto aos indicadores leva a valorização dos primeiros lugares: espaço dado para alunos, escolas e sistemas que obtém um desempenho favorável nas avaliações. As notícias sobre os primeiros lugares trazem como pano de fundo, via de regra, a cultura da performatividade expressa pela valorização de professores, alunos, instituições e sistemas que estão inseridos dentro dos índices (Revista Veja, "Campeões do Provão", 21/3/2001; "As lições da nota 100", 19/12/2001; "Quatro horas de estudo por dia", 11/02/2004; "Medir, avaliar e premiar", acompanhada pela síntese "O novo pacote de Lula para a educação promete resolver o atraso brasileiro de um jeito sensato: premiando o mérito" - 02/05/2007).

Na mesma direção, há a ênfase nas comparações e ranqueamentos que desembocam, via de regra, na elaboração de denúncias acerca da qualidade do ensino ministrado nos sistemas ou instituições que obtiveram um resultado (uma performance) abaixo do esperado (Revista Veja, "A média foi só 3,6", 17/12/2003; "Assim vai mal”, 15/12/2004; "As escolas campeãs", 22/02/2006; ou ainda Revista Época, "Estudo revela que mais de 44\% dos alunos não aprendem a ler direito", 16/04/2003).

Por sua vez, comparações, valorização dos primeiros lugares e rankings restam por estabelecer modelos (Revista Veja, "Modelo de Educação", 19/08/1998; "Um bom exemplo", 13/01/1999; "Viva a periferia", 7/3/2001; "As melhores da turma", 05/05/2004; "Escola pública, gestão particular", 14/02/2007; "Lição bem-feita", 05/12/2007; Revista Época, "Um modelo no campo", 01/07/2004; Revista Isto É, "Heróis da resistência”, 13/10/2000, etc...) sem espaço para uma reflexão circunstanciada sobre a conjuntura de desenvolvimento das instituições e sistemas "modelares"; tais modelos são sempre acompanhados de dicas e procedimentos para pais e educadores, além da opinião de especialistas sobre o assunto (raramente nominados, definidos genericamente como "especialistas no assunto dizem..."; "especialistas em alfabetização recomendam...").

As avaliações em larga escala prosperaram como discurso e prática agregada ao controle de mercado (oferta/procura; cliente/serviço; custo/benefício...), na medida em que

[...] a avaliação legitima "valorações" úteis à indução de procedimentos competitivos entre escolas e sistemas para melhorar pontuações nos rankings, definidos basicamente pelos desempenhos em instrumentos de avaliação em larga escala. Tal competição é garantida pela associação entre desempenho e financiamento, podendo redundar em critérios para alocação de recursos, que incidem, até mesmo, em remunerações diferenciadas dentro de sistemas de ensino que até há pouco trabalhavam com a noção de remunerações isonômicas... (SOUZA; OLIVEIRA, 2003, p. 876).

Isso porque há um componente ideológico fortemente agregado a qualquer modalidade de avaliação, em especial às avaliações de redes e sistemas de ensino, uma vez que 
Nas relações sociais capitalistas a avaliação cumpre hegemonicamente papel estratégico na disseminação de valores e finalidades de mercado que consubstanciam processos de gestão de natureza contábil e /ou de economização da educação. (OZGA, 2000, p. 10).

Esses processos de gestão de natureza contábil e /ou de economização da Educação a que se refere Ozga, incentivam a produção fordista como elemento de comparação e ranqueamentos, onde uma instituição, um aluno, um sistema não são avaliados em relação aos seus próprios progressos (luta histórica dos defensores da chamada avaliação dialógica), mas sim em contraposição com outros pretensamente iguais.

Nessa direção, Vianna (2003, p. 58), alerta que

[...] a comparação se faz pelo simples hábito de comparar, pois desta comparação nada efetivamente resulta, salvo maliciosos comentários de alguns segmentos da mídia, tendo em vista suas implicações [...] Além dos aspectos sociais e econômicos, precisamos atentar para a diversidade das características dos sistemas educacionais em diferentes regiões, a natureza dos currículos, a formação e experiência do corpo docente. Diante desse quadro, podemos fazer comparações e imaginar que os indivíduos poderiam ter os mesmos conhecimentos e as mesmas capacidades.

Ao gosto do neoliberalismo, a tendência de comparar, medir, ranquear acabou por promover uma pressão/cobrança externa sobre as escolas que, em geral, não corresponde à pressão por democracia no interior das mesmas, ou sequer pela melhoria das relações entre os membros da comunidade educativa ou das condições de trabalho docente.

A lógica é competir, instaurar comparações e adotar medidas de correção de resultados, justificando que "políticas de melhoria da escola centradas essencialmente na avaliação do rendimento dos alunos e em sua publicização para os pais [...] tendem fortemente para o lado da pressão e dos estímulos ao rendimento". (LESSARD, 2006, p. 231).

Como terceira categoria, percebe-se um empenho dos produtos midiáticos examinados em passar fórmulas e sugestões para o sucesso individual nas edições das avaliações de larga escala, como nas reportagens da Revista Veja: "Os meIhores da turma" (29/5/2002); "A receita dos bons alunos" (26/05/2004); "Do zero ao topo do ranking", (11/07/2007), da Revista Época, nos produtos midiáticos "Como fazer seu filho chegar lá" (26/06/2003); "Evento mostra como a educação pode estimular nos jovens o espírito empreendedor" (27/05/2004); "Ela gabaritou o Enem" (01/12/2007), ou ainda na Revista Isto É, nas reportagens "Bê-á-bá no bote- co" (24/04/1996) ou "Uma ponta de esperança" (13/08/2003). Prescreve-se um receituário para meIhorar o desempenho e a performance diante das aferições proporcionadas pelas avaliações de larga escala. Via de regra, tais receitas desenvolvem uma apologia ao esforço desmedido e a valorização da competição, abnegação e superação individual, sem auxílio externo do sistema (no caso de escolas) ou de professores (no caso de alunos).

Alguns produtos midiáticos, entretanto, revelam mais do que fórmulas, como na reportagem "Mestres de Elite" (Revista Veja, 16/12/1998), que faz referência a professores altamente qualificados e que recebem por desempenho na realidade da educação privada, "gente que ganha muito bem por ser mão de obra altamente qualificada", menciona a reportagem. São profissionais envolvidos na chamada "pedagogia de resultados", sinal dos tempos da performatividade.

Aliás, nos tempos da performatividade a mídia insiste em fazer uma separação, uma diferenciação em seu discurso entre os responsáveis pela Educação e os "consumidores" dos serviços educacionais, deixando clara a diferença entre uns (professores e gestores) e outros (pais e sociedade em geral), acentuado pelo uso do imperativo nas reportagens que falam sobre como os pais devem se relacionar com a escola e os professores dos seus filhos: a escola pública está assim; mas os pais "devem"; "faça isso"; "pergunte aquilo"; ou "Se a oferta parecer vantajosa demais, desconfie" (Revista Veja, "As armadiIhas dos cursos", 31/03/1999).

Os argumentos em torno do desempenho são notórios nos excertos empíricos examinados (e aqui ilustrados). As receitas para uma "boa" escola; as condições do "professor ideal" (competitivo e produtivo), assim como a priorização das escalas e ordenações entre estabelecimentos escolares são a tônica do discurso midiático performático.

\section{Conclusões provisórias}

A avaliação poderia, sem qualquer susto de ordem epistemológica, figurar no panteão das necessidades básicas humanas. Vivemos sob o imperativo constante de avaliar situações, pessoas, conjunturas. Avaliamos a todo o instante e, seguramente, "desde o início do processo civilizatório houve alguma forma de avaliação. Ousaríamos dizer que a avaliação surgiu com o próprio homem". (VIANNA, 2000, p. 22). Todavia, a questão de fundo é: o que fazemos e a quem servimos com o resultado de nossas avaliações?

As avaliações em larga escala - como fenômenos contemporâneos que refletem escolhas e 
Performatividade e educação: a política das avaliações em larga escala e a apropriação...

instrumentos de políticas educacionais -, são frutos da conjunção de três fatores: a tendência internacional de "ranquear" e produzir informações através da aferição da aprendizagem; a necessidade de se constituir instrumentos que permitam a gestores, educadores e a sociedade civil um feedback situacional da Educação e, como terceiro fator, a configuração do Estado avaliador. Tal configuração, em termos políticos, representou a sustentação ideológica para a performatividade, através, sobretudo, dos mecanismos de avaliação externa.

Como síntese e no escopo de tomar e "tornar a mídia inteligível" (SILVERSTONE, 2002, p. 283), fica patente ainda a presença da mídia enquanto "meio", intercessor entre os fatos e o público, indicando posicionamentos para esse público tomar diante dos fatos. É a mídia que, em grande medida, centraliza o debate da performatividade para a sociedade, quando se trata de Educação.

A mídia também potencializa o caráter de performatividade das avaliações de larga escala, no contexto do Estado avaliador, na medida em que torna público e, portanto, relevante, os índices e indicadores de escolas e sistemas de ensino, focalizando a competição e o desempenho como parâmetros de qualidade.

Há, por fim, um discurso patente que envolve a superação, o desafio, o altruísmo, e a meritocracia como forma de obter resultados desejáveis nas avaliações de larga escala, valorizando de sobremaneira os resultados conquistados em nível individual como elementos exemplares da postura que será necessária para vencer no Estado avaliador através dos critérios da performatividade.

\section{Referências}

AFONSO, A. J. Avaliação educacional: regulação e emancipação. 4. ed. São Paulo: Cortez, 2009.

BALL, S. J. Reformar escolas/reformar professores e os terrores da performatividade. Revista Portuguesa de Educação, Minho, v. 15, n. 2, p. 3-23, 2002.

BARRETTO, E. S. S. de; PINTO; R. P.; MARTINS, A. M.; DURAN, M. C. G. Avaliação na educação básica nos 90 segundo os periódicos acadêmicos. Cadernos de Pesquisa, São Paulo, n. 114, p. 49-88, nov. 2001.

FREITAS, A. F. R. de. Mídia e educação: campos em conflito em Portugal. In: REUNIÃO ANUAL DA ANPED, 32., 2009, Caxambu. Anais... Caxambu: ANPED, 2009. p. $1-13$.

GOMES, C. A. A escola de qualidade para todos: abrindo as camadas da cebola. Ensaio: avaliação e políticas públicas em educação, Rio de Janeiro, v. 13, n. 48, p. 281306, jul./set. 2005.

GOMES NETO, J. B.; ROSENBERG, L. Indicadores de qualidade do ensino e seu papel no Sistema Nacional de
Avaliação. Em Aberto, Brasília, v. 15, n. 66, p. 13-28, abr./ jun. 1995.

HADJI, C. A avaliação, regras do jogo. Porto: Porto Editora, 1994.

LESSARD, C. A universidade e a formação profissional dos docentes: novos questionamentos. Educação \& Sociedade, Campinas, v. 27, n. 94, p. 223-240, jan./abr. 2006.

KELLNER, D. A cultura da mídia. Estudos culturais: identidade e política entre o moderno e o pós-moderno. Tradução de Ivone Castilho Benedetti. Bauru: Edusc, 2002.

MARCONDES FILHO, C. Comunicação e jornalismo: a saga dos cães perdidos. São Paulo: Hacker editores, 2000.

MELO, J. M. de. A opinião no jornalismo brasileiro. Petrópolis: Vozes, 1994

OLIVEIRA, R. P. de; ARAUJO, G. C. de. Qualidade do ensino: uma nova dimensão da luta pelo direito à educação. Revista Brasileira de Educação, Campinas, n. 28, p. 5-23, jan./abr. 2005.

OZGA, J. Investigação sobre políticas educacionais: terreno de contestação. Porto: Porto Editora, 2000.

SANTOS, B. S. de. Pela mão de Alice: o social e o político na pós-modernidade. 2. ed. São Paulo: Cortez, 1996.

SANTOS, L. L. de C. Formação de professores na cultura do desempenho. Revista Educação \& Sociedade, Campinas, v. 25, n. 89, p. 1145-1157, set./dez. 2004.

SHIROMA, E. O.; MORAES, M. C. M de.; EVANGELISTA, O. Política Educacional. 2. ed. Rio de Janeiro: DP\&A, 2002.

SILVERSTONE, R. Por que estudar a mídia? São Paulo: Edições Loyola, 2002.

SILVA, J. M. da. A miséria do jornalismo brasileiro: as (in)certezas da mídia. 2. ed. Petrópolis: Vozes, 2001.

SOUZA, S. Z. L. de; OLIVEIRA, R. P. de. Políticas de avaliação da educação e quase mercado no Brasil. Educação \& Sociedade, Campinas, v. 24, n. 84, p. 873-895, set. 2003.

THOMPSON, J. B. A mídia e a modernidade: uma teoria social da mídia. 3. ed. Petrópolis: Vozes, 2001.

VIANNA, H. M. Avaliação Educacional. São Paulo: IBRASA, 2000.

Avaliação em debate. Brasília: Plano, 2003.

WAISELFISZ, J. Sistemas de avaliação do desempenho escolar e políticas públicas. Ensaio: avaliação e políticas públicas em educação, Rio de Janeiro, v. 1, n. 1, p. 5-22, dez. 1993.

\section{Fontes:}

Revista Isto É (1996-2007)

Revista Veja (1996-2007)

Revista Época (2003-2007)

Recebido em 10/03/2010

Versão final recebida em 24/09/2010

Aceito em 27/09/2010 